\title{
Diagnosis and evaluation of mitral valve disease using transseptal Doppler ultrasound catheterization
}

\author{
D. Kalmanson, Colette Veyrat, A. Bernier, C. H. Savier, P. Chiche, and S. Witchitz \\ From the Departments of Cardiology, Hôpital Tenon and Fondation Ophtalmologique A. de Rothschild, Paris, \\ France
}

In 33 patients with confirmed mitral valve disease, the mitral valve flow velocity traces were recorded by means of a directional Doppler ultrasonic velocimeter using the transseptal route, and correlated with the clinical and haemodynamic data. In all cases, characteristic anomalies of the mitral flow velocity patterns were noted and could be related to the type of lesion, stenosis, regurgitation, or a combination of these. Furthermore, specific patterns of the flow velocity traces were shown to correlate satisfactorily with the degree of severity of the disease. The authors propose a pathophysiological interpretation of the anomalies of the velocity patterns, based on turbulence for stenosis and backward flow wave for regurgitation. They conclude that the transseptal directional Doppler catheterization provides a new reliable method for establishing the diagnosis and grading the severity of mitral valve disease using pattern recognition, and, moreover, offers a new approach to the understanding of mitral haemodynamic disturbances on a beat-to-beat basis.

In the first part of this report (Kalmanson et al., I975), we demonstrated the possibility of recording blood flow velocity tracings of the normal mitral valve in patients by means of a directional Doppler ultrasonic catheter tip velocimeter placed at the site of the mitral annulus using the transseptal catheterization procedure.

The purpose of the present report is to demonstrate the value of this new technique for diagnosing and evaluating mitral valve disease, using a pattern recognition method.

\section{Subjects and methods}

Thirty-three patients were studied, $\mathrm{I} 7$ women and $\mathrm{I} 6$ men, ranging in age from 21 to 69 years (Table 1,2 , 3). They included 15 patients with pure mitral stenosis, 8 with pure mitral regurgitation, and to with associated mitral stenosis and regurgitation of rheumatic origin, some of whom had had bacterial endocarditis; I2 had associated aortic and/or tricuspid valve lesion; I8 were in sinus rhythm; and 15 were in atrial fibrillation. All patients underwent a routine diagnostic catheterization of the left heart using the transseptal route and the Telco ${ }^{1}$ manometer, according to Forman's technique (Forman, Laurens, and Servelle, 1962). Both atrial and ventricular pressures were recorded successively or

${ }^{1}$ Telco, 94-Gentilly, France.

Received ro July 1974. simultaneously allowing the measurement of the LA-LV pressure gradient. Cardiac output and mitral regurgitation were measured by the dye (indocyanine green) dilution technique using the Waters ${ }^{1}$ apparatus. Mitral valve area was calculated using the Gorlin formula with correction for any mitral regurgitation which was demonstrated.

\section{Classification of patients}

We used 4 grades of severity: (o: no lesion, $\mathrm{r}:$ mild, 2 : moderate, 3: severe.) The classification for the pure or predominant lesion on this four-point scale was based partly on the severity of the symptoms, and partly on the clinical presentation (bedside examination, $x$-ray, electrocardiogram, and clinical course) as well as on the haemodynamic data. For mitral stenosis, grading was based on the LA-LV pressure gradient and particularly on the calculated mitral area: greater than $1.5 \mathrm{~cm}^{2}$ for grade $I$, between $I .5$ and $I \mathrm{~cm}^{2}$ for grade 2 , and less than I $\mathrm{cm}^{2}$ for grade 3, it being understood that borderline cases may occasionally overlap these categories. For mitral regurgitation: large ' $v$ ' atrial wave, dye dilution curves, and angiocardiography, and for both lesions, surgical findings, when appropriate. Associated lesions of the mitral valve were also classified in 4 grades depending on the clinical and haemodynamic data, and surgical findings. The haemodynamic data are summarized in the Tables.

\footnotetext{
${ }^{1}$ Waters, Rochester, Minnesota, U.S.A.
} 
TABLE I Haemodynamic data of patients with pure mitral stenosis

\begin{tabular}{|c|c|c|c|c|c|c|c|c|}
\hline $\begin{array}{l}\text { Case } \\
\text { No. }\end{array}$ & Symptoms & Rhythm & $\begin{array}{l}L A \text { pressur } \\
(m m H g)(k \\
S / D\end{array}$ & Mean & $\begin{array}{l}L V \text { pressure } \\
(m m H g)(k P a \\
S / D\end{array}$ & a) & $\begin{array}{l}L A-L V \\
\text { pressure } \\
(m m H g)(k P a)\end{array}$ & $\begin{array}{l}\text { Calculated } \\
\text { mitral area } \\
\left(\mathrm{cm}^{2}\right)\end{array}$ \\
\hline I & ++ & AF & $\begin{array}{l}10 / 4 \\
I .3 / 0.5\end{array}$ & & $\begin{array}{l}106 / 2 \\
I 4.1 / 0.3\end{array}$ & $\begin{array}{l}-4 \\
-0.5\end{array}$ & $\begin{array}{l}5.7 \\
0.7\end{array}$ & I.7 \\
\hline 2 & ++ & SR & $\begin{array}{l}19 / 10 \\
2.5 / 1.3\end{array}$ & $\begin{array}{r}14 \\
1.8\end{array}$ & $\begin{array}{l}109 / 3 \\
14.5 / 0.4\end{array}$ & $\begin{array}{l}8 \\
I . I\end{array}$ & $\begin{array}{l}8 \\
I . I\end{array}$ & 2.3 \\
\hline 3 & ++ & SR & $\begin{array}{l}12 / 7 \\
1.6 / 0.9\end{array}$ & & $\begin{array}{l}200 / 0 \\
26.6 / 0\end{array}$ & $\begin{array}{l}5 \\
0.6\end{array}$ & $\begin{array}{l}2 \\
0.3\end{array}$ & 2.5 \\
\hline 4 & ++ & SR & $\begin{array}{l}20 / 14 \\
2.6 / 1.8\end{array}$ & $\stackrel{13}{1.7}$ & $\begin{array}{l}124 / 6 \\
16.5 / 0.8\end{array}$ & $\begin{array}{l}-8 \\
-I . I\end{array}$ & $\begin{array}{l}9 \\
1.2\end{array}$ & 0.9 \\
\hline 5 & +++ & $\mathrm{AF}$ & $\begin{array}{l}35 / 18 \\
4.6 / 2.4\end{array}$ & 20 & $\begin{array}{c}220 / 0 \\
29.2\end{array}$ & $\begin{array}{l}10 \\
1.3\end{array}$ & $\begin{array}{l}17 \\
2.3\end{array}$ & 0.4 \\
\hline 6 & +++ & SR & $\begin{array}{l}5 / 2.5 \\
0.6 / 0.3\end{array}$ & $\begin{array}{l}3 \\
0.4\end{array}$ & $\begin{array}{l}122 /-2 \\
16.2 /-0.2\end{array}$ & $\begin{array}{l}\mathrm{I} \\
0 . I\end{array}$ & $\begin{array}{l}3.2 \\
0.4\end{array}$ & I \\
\hline 7 & +++ & SR & $\begin{array}{l}22 / 8 \\
2.9 / I . I\end{array}$ & 10 & $\begin{array}{l}136 / 0 \\
18.1 / 0\end{array}$ & $\begin{array}{l}6 \\
0.8\end{array}$ & $\begin{array}{l}3 \\
0.4\end{array}$ & 1.8 \\
\hline 8 & +++ & AF & $\begin{array}{l}22 / 10 \\
2.9 / 1.3\end{array}$ & 15 & $\begin{array}{l}130 /-4 \\
17.3 /-0.5\end{array}$ & $\begin{array}{l}4 \\
0.5\end{array}$ & $\begin{array}{l}9 \\
1.2\end{array}$ & I.O \\
\hline 9 & + & SR & $\begin{array}{l}9 / 4 \\
1.2 / 0.5\end{array}$ & $\begin{array}{l}7 \\
0.9\end{array}$ & $\begin{array}{l}93 /-3 \\
12.3 /-0.4\end{array}$ & $\begin{array}{l}3 \\
0.4\end{array}$ & $\begin{array}{l}4 \\
0.5\end{array}$ & I.4 \\
\hline Io & $++t$ & SR & $\begin{array}{l}15 / 8 \\
I .9 / I . I\end{array}$ & $\begin{array}{l}9 \\
1.2\end{array}$ & $\begin{array}{l}122 / 0 \\
16.2 / 0\end{array}$ & $\begin{array}{l}8 \\
I . I\end{array}$ & $\begin{array}{l}6.4 \\
0.8\end{array}$ & 1.2 \\
\hline II & ++ & SR & $\begin{array}{l}17 / 10 \\
2.2 / 1.3\end{array}$ & 12 & $\begin{array}{l}134 / 5 \\
17.8 / 0.6\end{array}$ & $\begin{array}{l}-6 \\
-0.8\end{array}$ & $\begin{array}{l}3 \\
0.4\end{array}$ & 1.9 \\
\hline 12 & + & SR & $\begin{array}{l}15 / 3 \\
1.9 / 0.4\end{array}$ & $\begin{array}{l}9 \\
1.2\end{array}$ & $\begin{array}{l}156 / 6 \\
20.7 / 0.8\end{array}$ & $\begin{array}{l}0 \\
0\end{array}$ & $\begin{array}{l}5 \\
0.6\end{array}$ & 2.7 \\
\hline 13 & ++ & SR & $\begin{array}{l}18 / 6 \\
2.4 / 0.8\end{array}$ & $\begin{array}{l}8 \\
I . I\end{array}$ & $\begin{array}{l}125 / 6 \\
16.6 / 0.8\end{array}$ & $\begin{array}{l}2 \\
0.3\end{array}$ & $\begin{array}{l}9.6 \\
1.3\end{array}$ & 1.5 \\
\hline I4 & ++ & SR & $\begin{array}{l}22 / 10 \\
2.9 / 1.3\end{array}$ & $\begin{array}{l}13 \\
1.7\end{array}$ & $\begin{array}{l}112 /-3 \\
1491-0.4\end{array}$ & $\begin{array}{l}2 \\
0.3\end{array}$ & $\begin{array}{l}11 \\
1.5\end{array}$ & 1.0 \\
\hline 15 & +++ & AF & $\begin{array}{l}24 / 16 \\
3.2 / 21.2\end{array}$ & $\begin{array}{l}19 \\
2.5\end{array}$ & $\begin{array}{l}104 /-2 \\
13.8 /-0.3\end{array}$ & $\begin{array}{l}8 \\
I . I\end{array}$ & $\begin{array}{l}16 \\
2.1\end{array}$ & I.I \\
\hline
\end{tabular}

LA: left atrium; LV: left ventricle; CI : cardiac index; MS: mitral stenosis; $M R$ : mitral regurgitation; TS: tricuspid stenosis; TR: tricuspid regurgitation; AS: aortic stenosis; AR: aortic regurgitation; ASD: atrial septal defect; S/D: systolic/diastolic; ED: end-diastolic. Figures in italics are pressures in SI units (kPa).

TABLE 2 Haemodynamic data of patients with pure mitral regurgitation

\begin{tabular}{|c|c|c|c|c|c|c|c|c|}
\hline $\begin{array}{l}\text { Case } \\
\text { No. }\end{array}$ & Symptoms & Rhythm & $\begin{array}{l}L A \text { pressure } \\
(m m H g)(k P a) \\
S / D\end{array}$ & Mean & $\begin{array}{l}L V \text { pressure } \\
(m m H g)(k P a) \\
S / D\end{array}$ & $E D$ & $\begin{array}{l}\text { Volume of } \\
\text { regurgitation } \\
(\% \text { of } C O)\end{array}$ & $\begin{array}{l}C I \\
l . m^{-1} m^{-2}\end{array}$ \\
\hline 16 & + & AF & $\begin{array}{l}26 / 6 \\
3.4 / 0.8\end{array}$ & 12 & $\begin{array}{l}140 / 6 \\
18.6 / 0.8\end{array}$ & $\begin{array}{l}6 \\
0.8\end{array}$ & 50 & 1.9 \\
\hline I7 & +++ & AF & $\begin{array}{l}24 ! 5 \\
3.2 / 0.6\end{array}$ & 12 & & & 50 & 1.4 \\
\hline 18 & +++ & AF & $\begin{array}{l}15 / 0 \\
I .9 / 0\end{array}$ & $\begin{array}{l}7 \\
0.9\end{array}$ & $\begin{array}{l}105 /-2 \\
13.91-0.3\end{array}$ & $\begin{array}{l}2 \\
0.3\end{array}$ & IO & 3.1 \\
\hline I9 & + & SR & $\begin{array}{l}10 / 4 \\
I .3 / 0.5\end{array}$ & $\begin{array}{l}8 \\
I . I\end{array}$ & $\begin{array}{l}110 / 0 \\
14.6 / 0\end{array}$ & $\begin{array}{l}3 \\
0.4\end{array}$ & 0 & 5.5 \\
\hline 20 & +++ & AF & $\begin{array}{l}28 / 6 \\
3.7 / 0.8\end{array}$ & $\begin{array}{l}35 \\
4.6\end{array}$ & $\begin{array}{l}112 / 0 \\
14.9 / 0\end{array}$ & $\begin{array}{l}30 \\
3.9\end{array}$ & 30 & 2.7 \\
\hline $2 I$ & + & SR & $\begin{array}{l}8 / 4 \\
1.1 / 0.5\end{array}$ & $\begin{array}{l}16 \\
2.1\end{array}$ & $\begin{array}{l}112 / 7 \\
14.9 / 0.9\end{array}$ & $\begin{array}{l}6 \\
0.8\end{array}$ & 20 & 2.5 \\
\hline 22 & ++ & SR & $\begin{array}{l}19 / 5 \\
2.5 / 0.6\end{array}$ & $\begin{array}{l}20 \\
2.6\end{array}$ & $\begin{array}{l}100 / 2 \\
13.3 / 0.3\end{array}$ & $\begin{array}{l}0 \\
0\end{array}$ & 30 & 1.8 \\
\hline 23 & + & SR & $\begin{array}{l}20 / 9 \\
2.6 / 1.2\end{array}$ & 12 & $\begin{array}{l}200 / 0 \\
26.6 / 0\end{array}$ & $\begin{array}{l}16 \\
2.1\end{array}$ & 7 & 2.2 \\
\hline
\end{tabular}

CO: cardiac output. For other abbreviations see Table $x$. 


\begin{tabular}{|c|c|c|c|c|}
\hline $\begin{array}{l}C I \\
l . m^{-1} m^{-2}\end{array}$ & $\begin{array}{l}M S \\
\text { grading }\end{array}$ & $M R$ & $\begin{array}{l}\text { Associated } \\
\text { lesions }\end{array}$ & Operation \\
\hline 2.6 & $\mathbf{I}$ & 0 & & - \\
\hline 1.9 & $\mathbf{I}$ & 0 & $\begin{array}{r}\text { Tricuspid } \\
\text { stenosis }\end{array}$ & - \\
\hline 2.3 & $\mathbf{I}$ & 0 & AS & - \\
\hline 2.7 & 3 & 0 & - & - \\
\hline 1.2 & 3 & 0 & TS, TR, AS & + \\
\hline I.I & 3 & 0 & - & - \\
\hline 2 & 2 & 0 & ASD & + \\
\hline 2.1 & 3 & 0 & - & + \\
\hline 2.9 & 2 & 0 & - & - \\
\hline 2.4 & 2 & 0 & TS & - \\
\hline 2.5 & I & 0 & - & - \\
\hline 4 & I & o & - & - \\
\hline 2.9 & 2 & 0 & - & + \\
\hline 2.3 & 3 & 0 & - & + \\
\hline 2.2 & 3 & 0 & AR & - \\
\hline
\end{tabular}

\begin{tabular}{llll}
\hline $\begin{array}{l}\text { MS } \\
\text { grading }\end{array}$ & $\begin{array}{l}\text { MR } \\
\text { grading }\end{array}$ & $\begin{array}{l}\text { Associated } \\
\text { lesions }\end{array}$ & Operation \\
\hline 0 & 3 & - & + \\
0 & 3 & - & + \\
0 & I & $\begin{array}{l}\text { Emphysema } \\
\text { Holosystolic } \\
\text { murmur at apex } \\
\text { decreased by } \\
\text { amyl nitrite }\end{array}$ & - \\
0 & I & $\begin{array}{l}\text { AR } \\
-\end{array}$ & - \\
0 & 3 & AR & - \\
0 & 2 & Hypertension & - \\
0 & 3 & I & \\
\hline & & & - \\
\hline
\end{tabular}

\section{Technique}

The technique has been described in detail in the first part of this report (Kalmanson et al., 1975). We used the directional Doppler ultrasonic Sonicaid BV $180^{1}$ velocimeter, previously described (Kalmanson et al., 1969). The catheter tip of the velocimeter was brought forward to the site of the mitral annulus using the transseptal route under fluoroscopic control and recordings were made at different points near the centre, the anterolateral, and, whenever possible, the posteromedial commissure. The traces were recorded during light respiration in unanaesthetized patients and inscribed on a four-channel 34 or seven-channel 8I Mingograf, direct ink-writing recorder, simultaneously with electrocardiogram lead II and frequency selected phonocardiogram at the second left intercostal space or at the apex. The chart speed was either 25 or $50 \mathrm{~mm} / \mathrm{s}$. The distance between two successive spikes (upper row in the figures) equals I $\mathrm{s}$.

\section{Results}

\section{Patients with pure mitral stenosis ( 15 cases)}

Apart from the normal initial negative deflection $i c$, the systolic segment of the curve closely followed the zero line, except with 2 patients (Cases 2 and 10). The diastolic part of the curve consistently showed anomalies of the $D$ wave, of various patterns depending on the severity of the stenosis.

a) Mild stenosis ( 5 cases) In all patients, the ascending limb of the $\mathrm{D}$ wave had a normal slope, reached a peak of normal amplitude but showed (Fig. I and 2) a series of small indentations, starting late, in the latter half of its ascent, either slightly before or at the peak itself, sometimes continuing on the descending limb of the $\mathrm{D}$ wave. These indentations were synchronous with the diastolic murmur on the phonocardiogram. In 4 cases, an isolated notch synchronous with the opening snap recorded on the phonocardiogram encroached on the beginning of the ascending limb of the $\mathrm{D}$ wave. The peak of the $D$ wave was usually either dome-shaped or like a plateau. The amplitude of the $A$ wave depended on the heart rate and was not usually high. In patients with atrial fibrillation, the mitral flow velocity patterns were similar to those of patients with sinus rhythm, except for the disappearance of the end-diastolic A wave.

b) Moderate stenosis ( 4 cases) The pattern found is shown in Fig. 3. Near the anterolateral commissure, the $\mathrm{D}$ wave has an upright ascending limb, but the indentations occur earlier, in mid-ascent. The peak of the D wave is not sharp but replaced by an irregular plateau. The $A$ wave is conspicuous and has the same amplitude as the $\mathrm{D}$ wave. At the centre of the mitral annulus, the velocities are greater but the general pattern remains similar.

\footnotetext{
1 Sonicaid, Bognor Regis, Sussex.
} 
TABLE 3 Haemodynamic data of patients with associated mitral stenosis and regurgitation

\begin{tabular}{|c|c|c|c|c|c|c|c|c|c|}
\hline \multirow{3}{*}{$\begin{array}{l}\text { Case } \\
\text { No. } \\
24\end{array}$} & \multirow{3}{*}{$\begin{array}{l}\begin{array}{l}\text { Symp- } \\
\text { toms }\end{array} \\
++\end{array}$} & \multirow{3}{*}{$\begin{array}{l}\text { Rhythm } \\
\text { SR }\end{array}$} & \multirow{2}{*}{\multicolumn{2}{|c|}{$\begin{array}{l}L A \text { pressure } \\
(m m H g)(k P a) \\
S / D \quad \text { Mean }\end{array}$}} & \multicolumn{2}{|c|}{$\begin{array}{l}L V \text { pressure } \\
(m m H g)(k P a)\end{array}$} & \multirow{3}{*}{\begin{tabular}{c}
$\begin{array}{l}L A-L V \\
\text { pressure } \\
(\mathrm{mmHg}) \\
(\mathrm{kPa})\end{array}$ \\
I0 \\
\multicolumn{1}{c}{$\mathrm{I}$}
\end{tabular}} & \multirow{2}{*}{$\begin{array}{l}\text { Calculated } \\
\text { mitral } \\
\text { area } \\
\left(\mathrm{cm}^{2}\right)\end{array}$} & \multirow[t]{2}{*}{$\begin{array}{l}C I \\
l m^{-1} m^{-2}\end{array}$} \\
\hline & & & & & & & & & \\
\hline & & & $\begin{array}{l}28 / 16 \\
3.7 / 2.1\end{array}$ & 20 & $\begin{array}{l}90 /-2 \\
I I .9 /-0.3\end{array}$ & $\begin{array}{l}2 \\
0.3\end{array}$ & & I. 3 & 2.6 \\
\hline 25 & ++ & $\mathrm{AF}$ & $\begin{array}{l}15 / 9 \\
I .9 / 1.2\end{array}$ & $\begin{array}{l}\text { II } \\
I .4\end{array}$ & $\begin{array}{l}100 / 0 \\
13.3 / 0\end{array}$ & $\begin{array}{l}4 \\
0.5\end{array}$ & $\begin{array}{r}12 \\
I .6\end{array}$ & 1.3 & \\
\hline 26 & +++ & AF & $\begin{array}{l}14 / 7 \\
1.8 / 0.9\end{array}$ & $\begin{array}{l}10 \\
1.3\end{array}$ & $\begin{array}{l}108 / 2 \\
14.3 / 0.3\end{array}$ & $\begin{array}{l}8 \\
I . I\end{array}$ & $\begin{array}{l}4 \\
0.5\end{array}$ & I. 2 & 2 \\
\hline 27 & +++ & $\mathrm{AF}$ & $\begin{array}{l}16 / 10 \\
2.1 / 1.3\end{array}$ & $\begin{array}{l}16 \\
2.1\end{array}$ & $\begin{array}{l}100 /-2 \\
13.3 /-0.3\end{array}$ & $\begin{array}{l}3 \\
3 \\
0.4\end{array}$ & $\begin{array}{l}10 \\
1.3\end{array}$ & I & 2.5 \\
\hline 28 & +++ & AF & $\begin{array}{l}25 / 12 \\
3.3 / 1.6\end{array}$ & $\begin{array}{l}19 \\
2.5\end{array}$ & $\begin{array}{l}158 / 0 \\
21.0 / 0\end{array}$ & 12 & $\begin{array}{l}4 \\
0.5\end{array}$ & I.6 & 3.6 \\
\hline 29 & ++ & AF & $\begin{array}{l}30 / 2 \\
3.9 / 0.3\end{array}$ & & $\begin{array}{l}82 / 2 \\
10.9 / 0.3\end{array}$ & $\begin{array}{l}-I \\
-O . I\end{array}$ & $\begin{array}{l}10 \\
1.3\end{array}$ & 0.9 & 2.I \\
\hline 30 & +++ & AF & $\begin{array}{c}10 / 2.5 \\
1.3 / 0.3\end{array}$ & $\begin{array}{l}6 \\
0.8\end{array}$ & $\begin{array}{l}90 /-1 \\
I I .9 /-0 . I\end{array}$ & $\begin{array}{l}\mathrm{I} \\
0 . I\end{array}$ & $\begin{array}{l}4 \\
0.5\end{array}$ & I & I.6 \\
\hline $3 I$ & ++ & SR & $\begin{array}{l}8 / 3 \\
1.1 / 0.4\end{array}$ & & $\begin{array}{c}126 / 0 \\
16.7 / 0\end{array}$ & $\begin{array}{l}-5 \\
-0.6\end{array}$ & $\begin{array}{l}4.2 \\
0.5\end{array}$ & 1.6 & 2.3 \\
\hline 32 & +++ & AF & $\begin{array}{l}20 / 10 \\
2.6 / 1.3\end{array}$ & $\begin{array}{l}15 \\
1.9\end{array}$ & $\begin{array}{l}154 / 4 \\
20.5 / 0.5\end{array}$ & $\begin{array}{l}0 \\
0\end{array}$ & $\begin{array}{l}2 \\
0.3\end{array}$ & 2.9 & 1.0 \\
\hline 33 & ++ & SR & $\begin{array}{l}15 / 10 \\
I .9 / 1.3\end{array}$ & 12 & $\begin{array}{l}103 / 5 \\
13.70 .6\end{array}$ & $\begin{array}{l}-I \\
-O . I\end{array}$ & $\begin{array}{l}9 \\
1.2\end{array}$ & I.I & 2.5 \\
\hline
\end{tabular}

For abbreviations see Table $\mathbf{I}$.

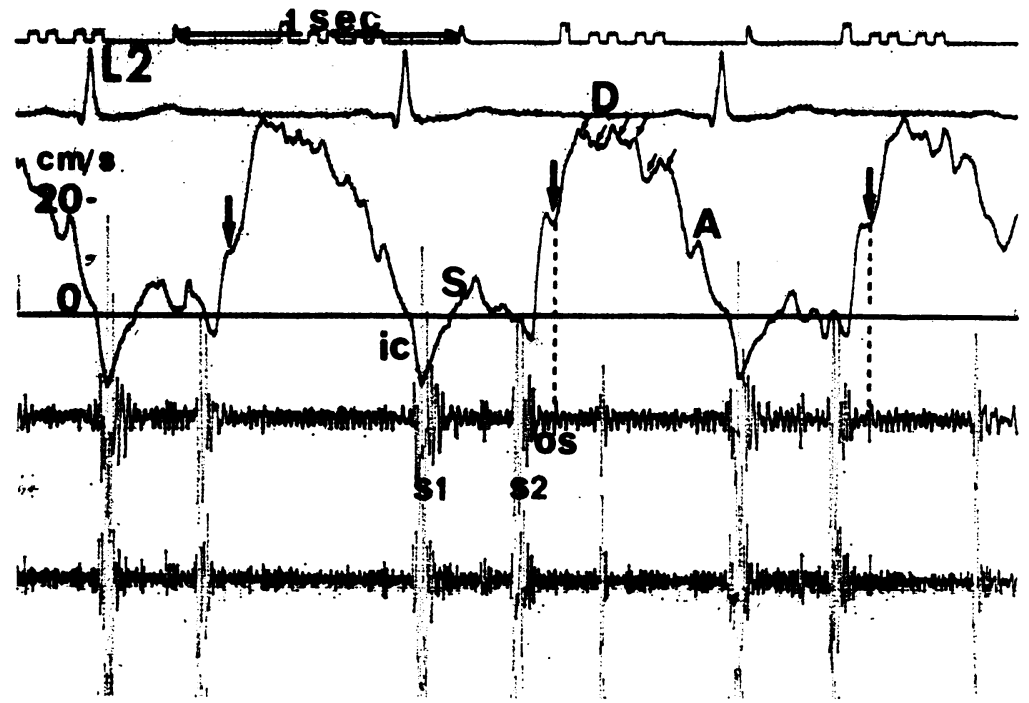

FI I I Mitral valve flow velocity trace in patient with pure mild stenosis. From top to bottom: Electrocardiogram lead II, flow velocity trace, and phonocardiogram. The systolic velocity component is normal: negative deflection (ic) during isometric contraction, $S$ segment along the zero line. The diastolic filling wave $D$ rises abruptly but is interrupted by a small conspicuous notch (arrow) synchronous with the opening snap (os), then continues to rise with a steep slope up to the peak. Small indentations occur, giving the peak an appearance of an irregular and slightly descending plateau. The indentations proceed on the descending limb of the $D$ wave. Heart rate is low, 54/min, and the $A$ wave is small (Case II, calculated mitral area: $\left.1.9 \mathrm{~cm}^{2}\right)$. 


\begin{tabular}{lllll}
\hline $\begin{array}{l}\text { Volume of } \\
\text { regurgi- } \\
\text { tation } \\
\text { (\% of CO) }\end{array}$ & $\begin{array}{l}\text { MS } \\
\text { grading }\end{array}$ & $\begin{array}{l}\text { MR } \\
\text { grading }\end{array}$ & $\begin{array}{l}\text { Associated } \\
\text { lesions }\end{array}$ & $\begin{array}{l}\text { Opera- } \\
\text { ation }\end{array}$ \\
\hline I0 & 3 & I & - & + \\
I0 & 3 & I & - & - \\
20 & 3 & 2 & TS, TR, AS & + \\
30 & 3 & 2 & AR & + \\
30 & 2 & 2 & AS & - \\
I0 & 3 & I & - & - \\
I0 & 3 & I & - & + \\
I0 & I & I & - & - \\
I0 & I & I & AS, AR & + \\
5 & 2 & I & AR & - \\
\hline
\end{tabular}

c) Severe stenosis (6 cases) (Fig. 4,5 , and 6) In all these patients, at the commissural areas, the D wave was noticeably decreased, with welldefined coarse indentations usually starting very early on the ascending limb. The ascending limb had a smaller slope than normal, the peak was either cut off with an irregular plateau of low amplitude, or conspicuously delayed. The A wave when present was as a rule higher than the $D$ wave. At the centre, the pattern resembled more that of moderate or even mild stenosis as the overall velocities were higher and as the indentations occurred only after an upright ascent of the $\mathrm{D}$ wave, the amplitude of which was conspicuously higher than that of the commissural velocity pattern.

Summarizing, in all these patients we found an anomalous pattern of the $\mathrm{D}$ wave, consisting of characteristic indentations giving a saw-tooth appearance to its ascending limb, its peak, or the descending limb, depending on the severity of the stenosis. The slope of the ascending wave was decreased in severe stenosis, the amplitude of the summit was more or less decreased, and its timing delayed. The anomalies were more pronounced near the commissural areas than near the centre of the mitral annulus, where the velocities tended to be higher, the ascending limb steeper, and the indentations occurred at a higher level (Fig. I, 6).

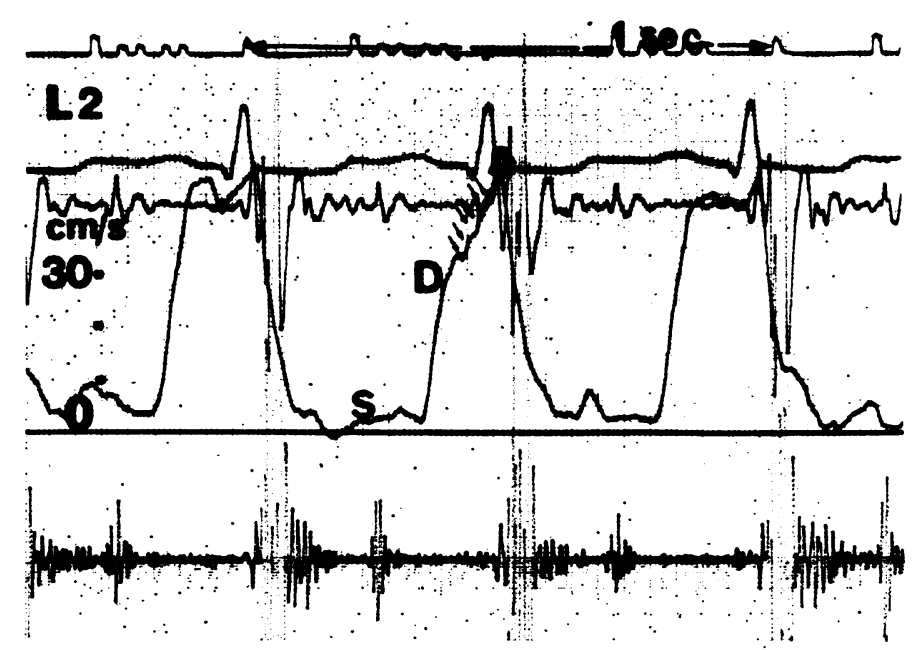

FIG. 2 Mitral valve flow velocity trace in patient with pure mild stenosis. Heart rate is high: I I $6 / \mathrm{min}$, and $D$ and $A$ waves are almost fused. The ascending limb of the $D$ wave is normal in slope and magnitude, but during the atrial contraction the slope is somewhat decreased, and small indentations appear synchronous with the end-diastolic vibrations on the phonocardiogram (Case I2, calculated mitral area: $2.7 \mathrm{~cm}^{2}$ ). 


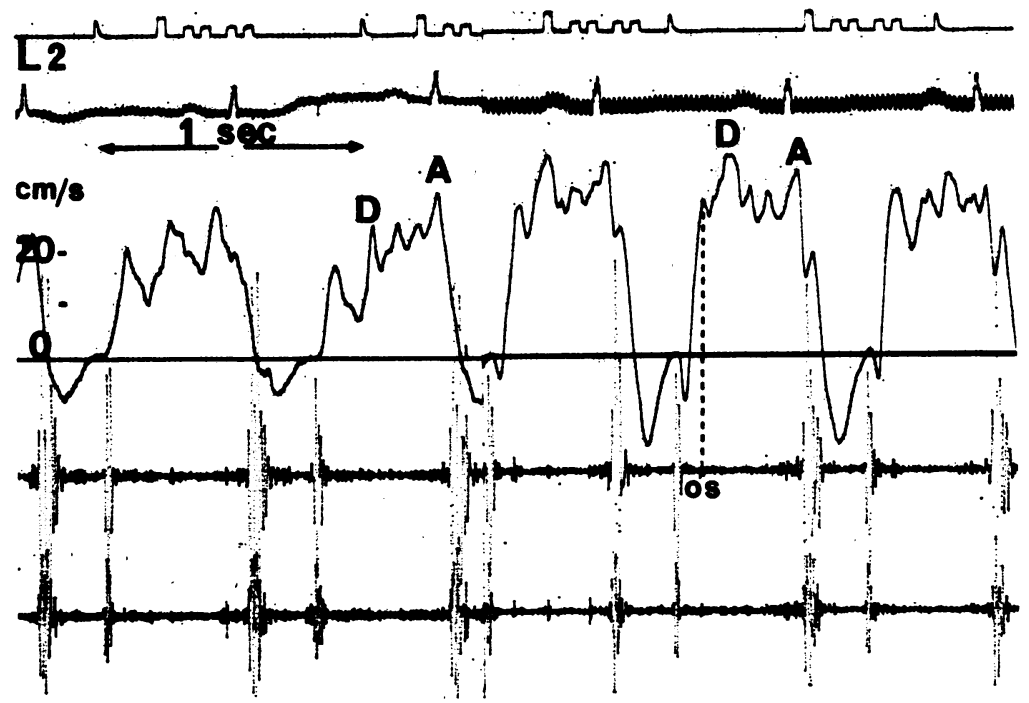

FI G. 3 Mitral valve flow velocity trace in a patient with pure moderate mitral stenosis. Left: near the anterolateral commissure: the $D$ wave starts erect, is suddenly interrupted by a conspicuous notch synchronous with the opening snap, then rises again but its peak is cut off and replaced by a coarsely irregular plateau. The $A$ wave is of higher magnitude than the $D$ wave. Right: in the centre of the mitral ring: the pattern is very similar but the peak of the $D$ wave is conspicuously higher. (Case 10, calculated mitral area: $1.2 \mathrm{~cm}^{2}$.)

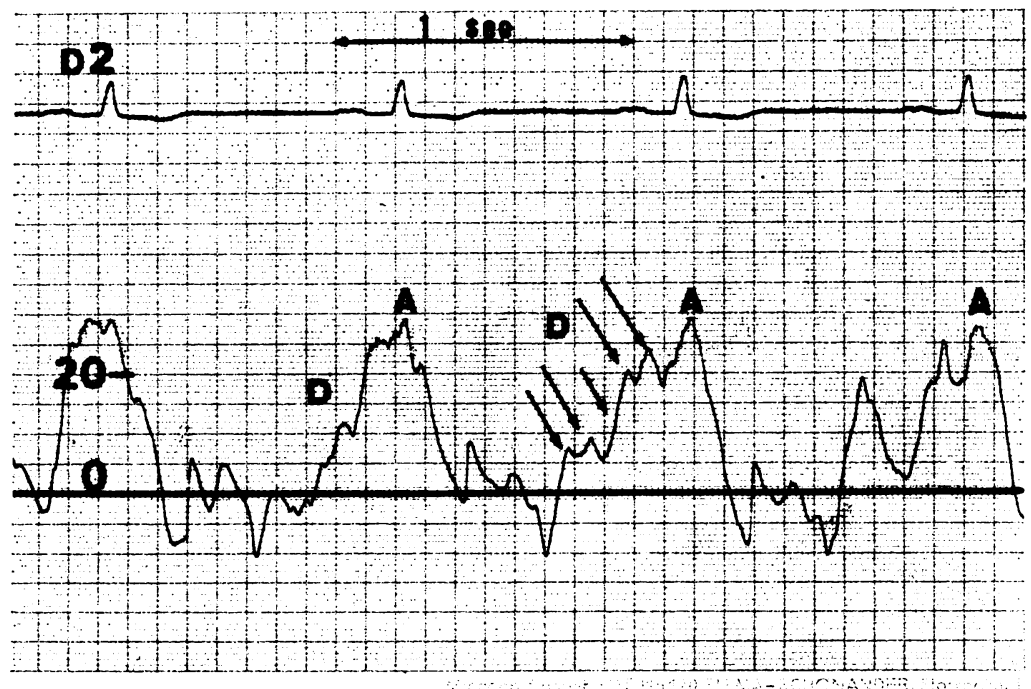

FIG. 4 Mitral valve flow velocity trace in a patient with a pure severe mitral stenosis (recording at the anterolateral commissure). The $D$ wave is replaced by a very irregular ascending curve, with a gradual slope, the $A$ wave is of higher amplitude than the $D$ wave (Case 6, calculated mitral area: $\mathrm{I} \mathrm{cm}^{2}$ ). 


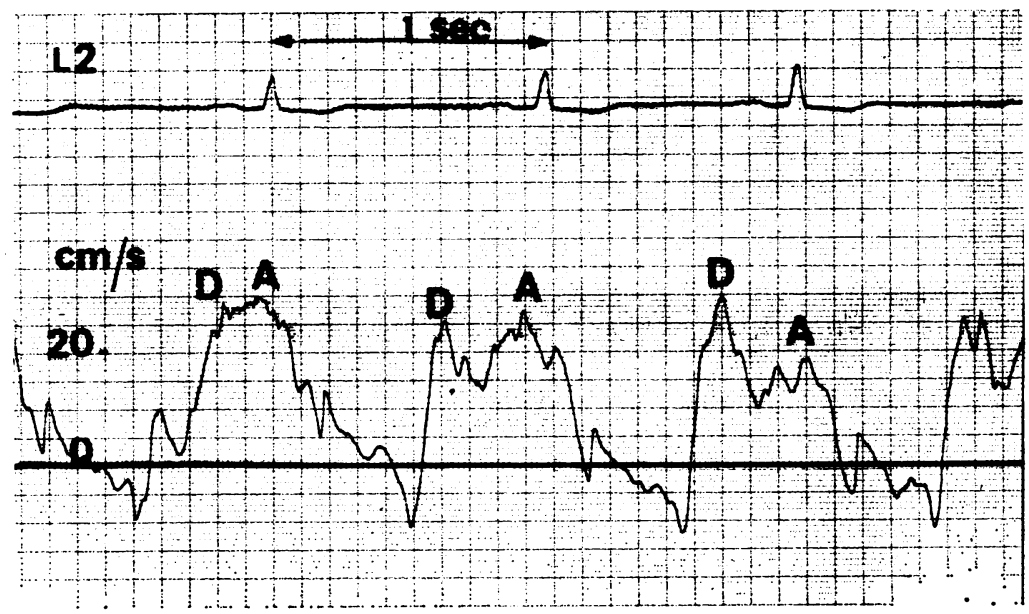

FIG. 5 Mitral valve flow velocity trace in a patient with pure severe mitral stenosis. Recording at the centre of the annulus (same patient as in Fig. 4). The D wave has a steep ascent and its peak is noticeably higher than that in Fig. 4.

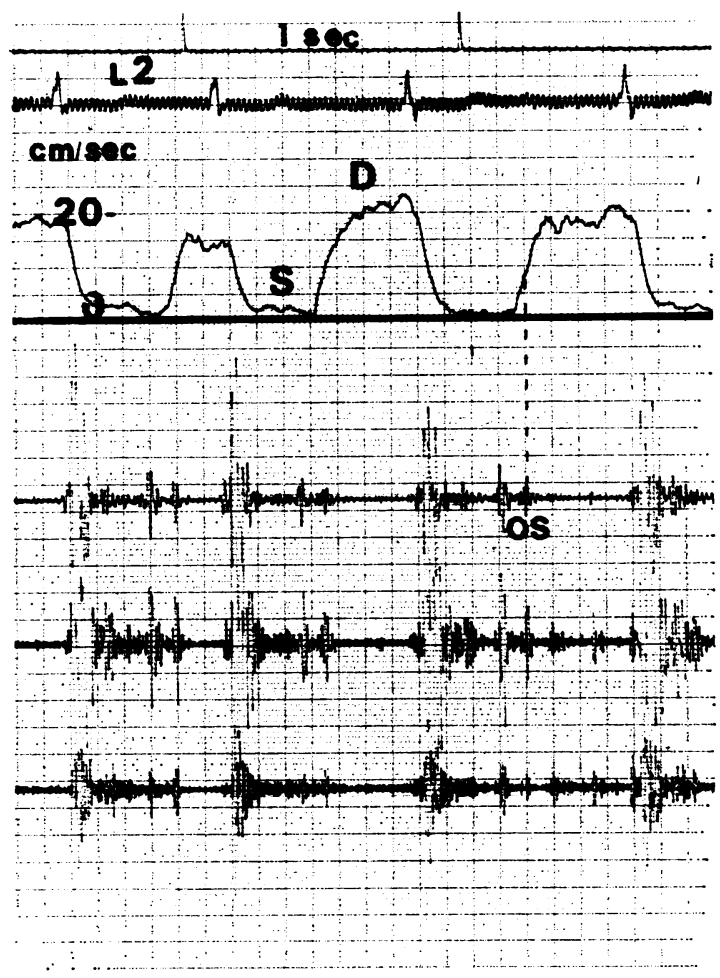

FIG. 6 Mitral valve flow velocity trace in a patient with pure severe mitral stenosis. The ascending limb of the $D$ wave starts with a lesser slope than normal, and decelerates early or is completely stopped; the $D$ wave shows a low and irregular plateau as its peak (Case 5, calculated mitral area: $0.4 \mathrm{~cm}^{2}$ ).
Patients with pure mitral regurgitation (8 cases)

In all these patients a partly or totally negative $S$ wave of varying amplitude was found.

a) Mild regurgitation (3 cases) (Fig. 7 and 8) In these patients a mid-systolic negative $S$ wave of low amplitude was found. In 2 patients, this negative wave was noted both at the commissures and at the centre of the annulus, where it was slightly deeper, and in one patient it was found only at one commissure, whereas elsewhere no negative wave could be recorded during systole. The diastolic waves $D$ and $A$ were normal.

b) Moderate regurgitation (I case) (Fig. 9) The $S$ wave was entirely negative, of moderate amplitude (10 $\mathrm{cm} / \mathrm{s})$, the $\mathrm{D}$ wave was slightly increased in magnitude, and showed irregular indentations, very variable in position, and of small amplitude.

c) Severe regurgitation (4 patients) (Fig. I0) We consistently found a large amplitude, negative systolic $S$ wave which was pansystolic and even extended in early diastole. The $D$ wave was increased in 2 cases, and decreased in the other 2 cases.

Summarizing, in all these patients we found a negative systolic wave either at all sites of recording or only at one particular point. The more severe the regurgitation, the greater the depth of the systolic wave. 


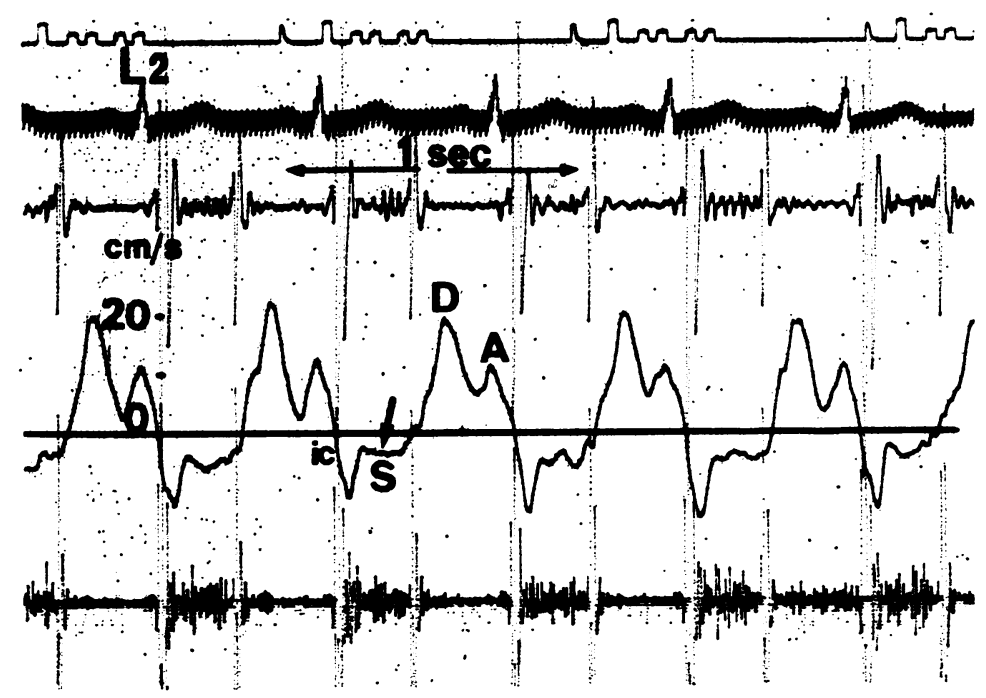

FIG. 7 Mitral valve flow velocity trace in a patient with a pure mild mitral regurgitation. After the initial negative deflection (ic), the $S$ segment of the curve rises again, without however reaching the zero line, and consistently remains slightly below that line throughout systole. The diastolic $A$ and $D$ waves remain normal.

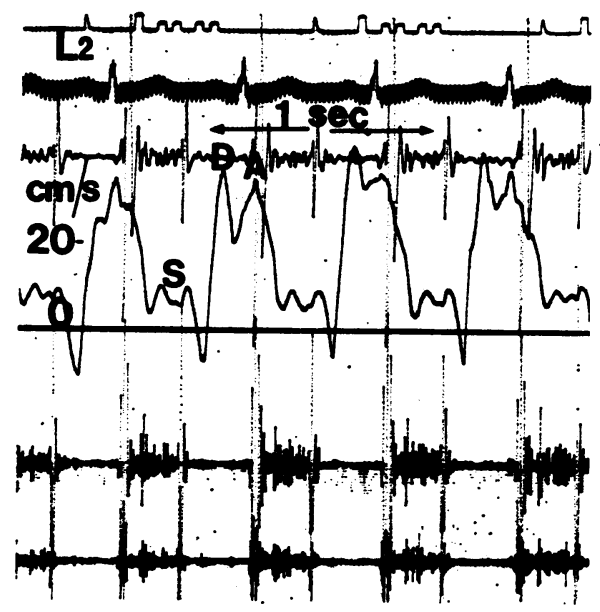

FIG. 8 Mitral valve flow velocity in a patient with a pure mild mitral regurgitation. Recording at the centre of the annulus (same patient as in Fig. 7). The systolic wave is no longer negative, and the velocities of the $D$ wave are conspicuously higher than in Fig. 7 .
Associated mitral stenosis and regurgitation (I0 cases)

a) Severe stenosis and mild regurgitation (3 cases) In two cases the traces showed (Fig. II) a slightly negative $S$ wave. The $D$ wave is almost lost and very irregular but there is a very high $A$ wave.

b) Severe stenosis and moderate regurgitation ( 2 cases) (Fig. 12) At all sites the systolic $S$ wave was negative throughout systole, and of moderate depth. The D wave showed typical indentations, was of low amplitude at the commissural areas, and of higher amplitude at the centre of the annulus.

c) Moderate stenosis and moderate or mild regurgitation (3 cases) Near the anterolateral commissure (Fig. 13), the D wave is decreased; its peak is cut off but the $S$ wave is not negative. At the centre of the annulus (Fig. 14) a negative systolic wave shows up, of moderate depth, and the D wave has a higher amplitude than in Fig. 13, its indentations are smaller and start later.

d) Mild stenosis and mild regurgitation (2 cases) (Fig. 15) The curve shows a small negative $S$ wave throughout systole, and late indentations occurring at the peak of the $D$ wave.

Discrepancies In 3 patients (Cases 2, I0, and I8), in whom the pressure data did not suggest any mitral regurgitation, but who all had clinical and 

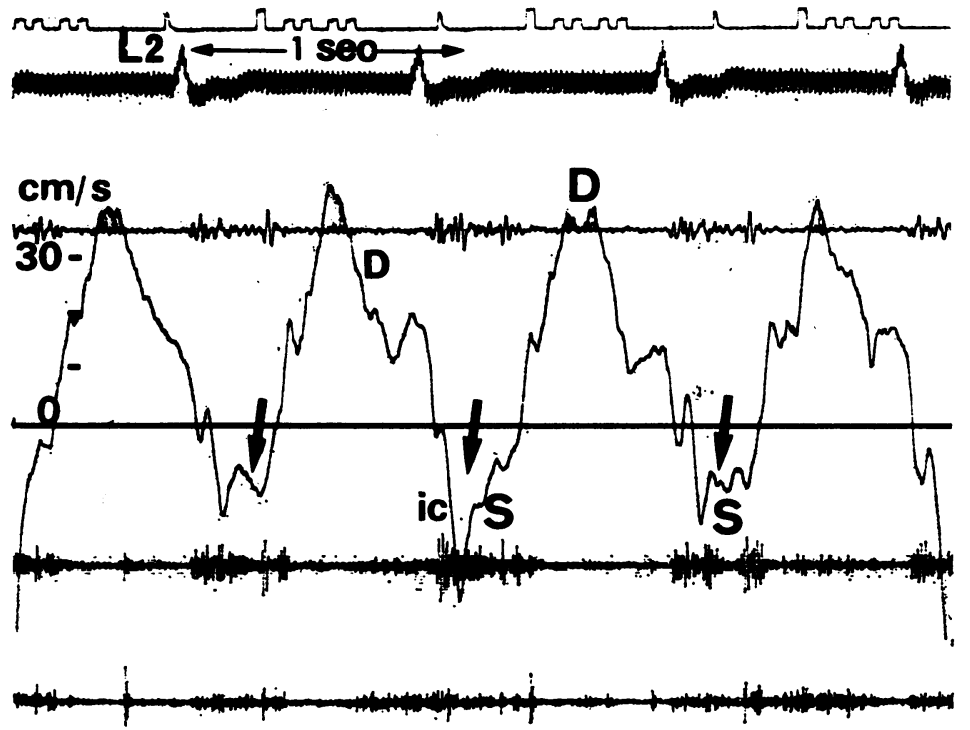

FIG. 9 Mitral valve flow velocity in a patient with a pure moderate mitral regurgitation. The pattern is similar to that of Fig. 7, but the depth of the $S$ wave is of greater amplitude. Furthermore, the magnitude of the $D$ wave is increased, and small indentations appear on its ascending limb (Case 21 : volume of regurgitation: $20 \%$ of cardiac output).

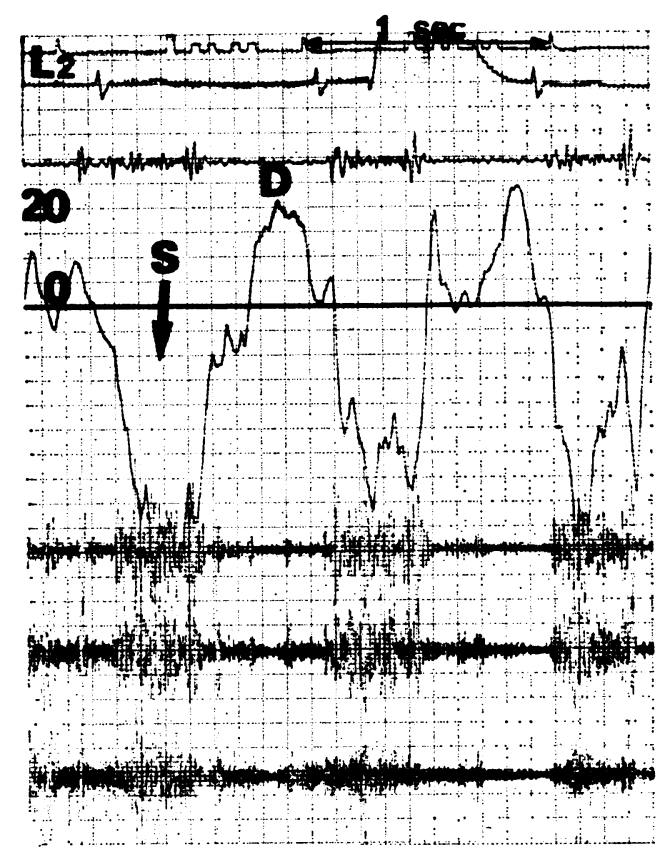

FIG. Io Mitral valve flow velocity trace in a patient with pure severe mitral regurgitation. The $S$ wave is replaced by a very deep negative wave throughout systole (Case 15: volume of regurgitation: $50 \%$ of cardiac output). phonocardiographic evidence of mitral regurgitation, the flow velocity traces showed a small negative wave during systole (left ventricular cineangiocardiography was not performed on these patients).

\section{Comments and discussion}

\section{Purpose of method}

It seems appropriate to mention at this stage that procedures currently used for investigating mitral valve disease give an incomplete and/or indirect picture of the haemodynamic disturbances in mitral valve disease: calculation of mitral valve areas depends on the knowledge of the amount of regurgitation. Dye dilution and thermodilution techniques are misleading in the presence of shunts or aortic regurgitation. Angiocardiography cannot be used to grade the severity of mitral stenosis, and its value in the assessment of mitral regurgitation is still debated. Echocardiography gives information on the movements of the valve cusps in one plane but gives no quantitative haemodynamic data. Finally, none of these techniques provides information about the basic phenomena, i.e. the beat-to-beat phasic transmitral flow disturbances. The recent advent of blood flow velocity measurement in patients within the right heart (Kalmanson, Derai, and Novikoff, I971; Kalmanson et al., I969) by use of a directional Doppler probe has led to a new method of 


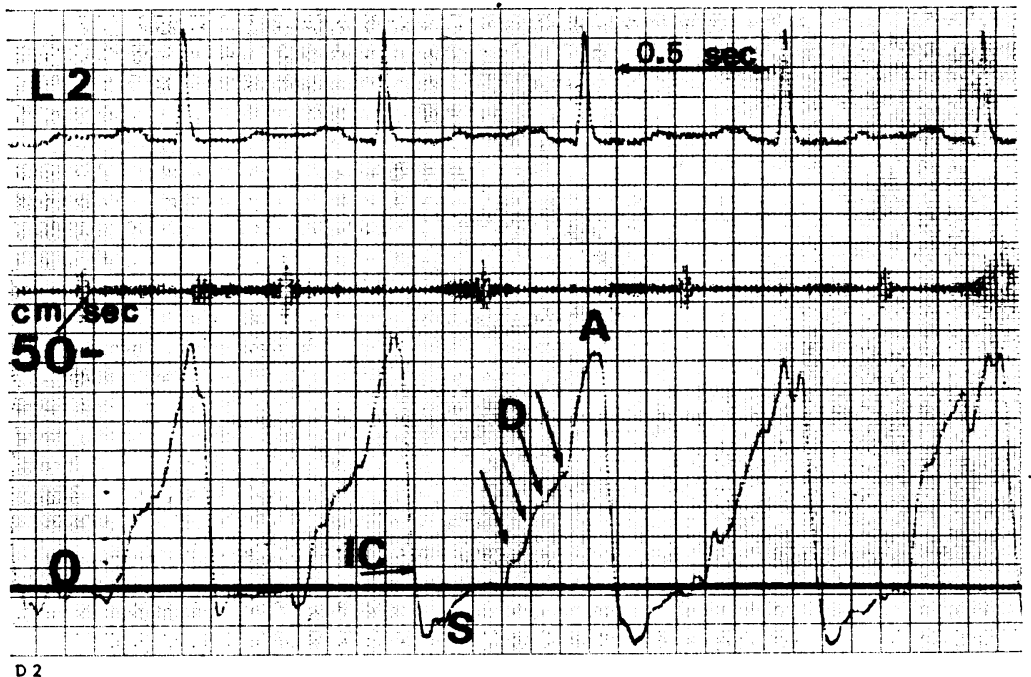

FIG. II Mitral valve flow velocity trace in a patient with severe mitral stenosis and mild regurgitation. There is a small negative $S$ wave and the $D$ wave is lost and replaced by a segment of smaller slope and disclosing indentations. The amplitude of the $A$ wave is increased (Case 24: calculated mitral area: $1.3 \mathrm{~cm}^{2}$ : volume of regurgitation: $10 \%$ of cardiac output)

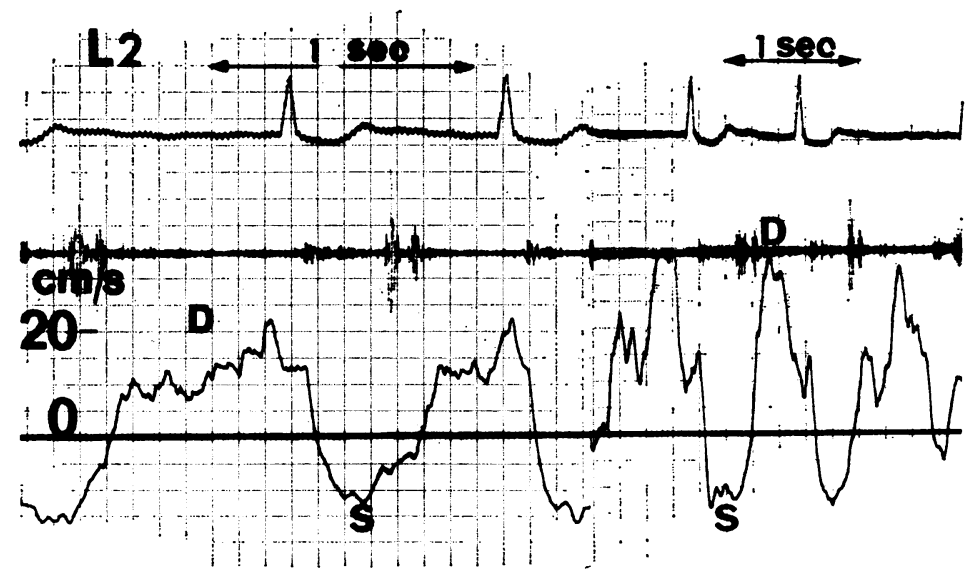

FIG. I2 Mitral valve flow velocity trace in a patient with severe stenosis and moderate regurgitation in atrial fibrillation. Left: at the commissural areas. Right: at the centre of the mitral annulus. In both tracings, the $S$ wave is negative throughout systole and of moderate depth. The $D$ wave is cut off near the commissures; it is of much higher amplitude at the centre of the annulus, and shows much less pronounced indentations (Case 30 , calculated mitral area: $1 \mathrm{~cm}^{2}$ : volume of regurgitation: $10 \%$ of cardiac output). 

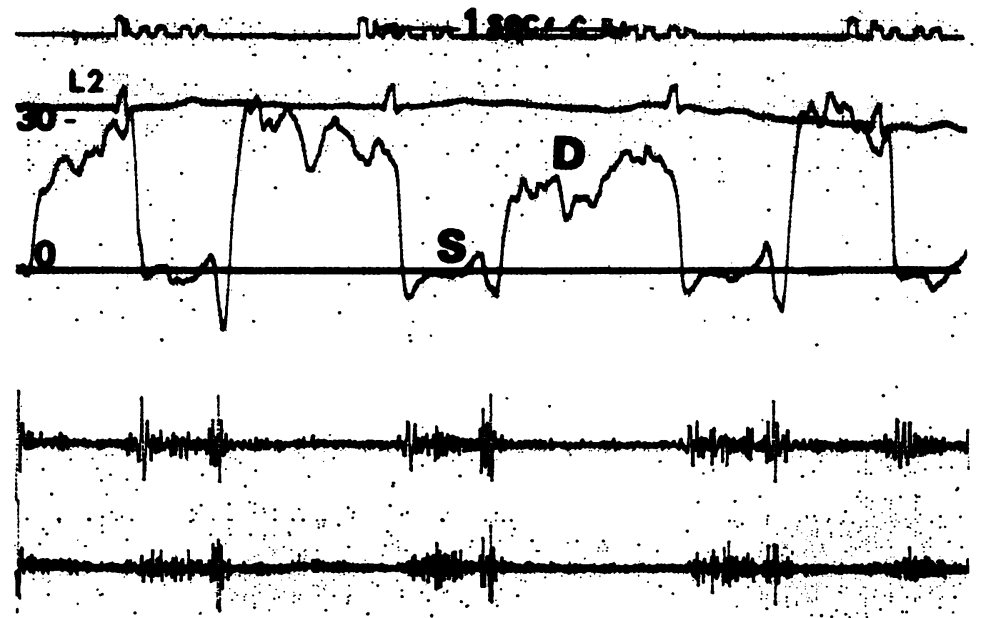

FIG. I3 Mitral valve flow velocity trace in a patient with moderate stenosis and a moderate central regurgitation. Recording at the anterolateral commissure. The $D$ wave has a steep ascent but its peak is cut off and shows characteristic indentations. Note that the systolic $S$ wave is not negative and remains close to the zero line. There is no regurgitation at the commissure (Case 26, calculated mitral area: $1.2 \mathrm{~cm}^{2}$, volume of regurgitation: $20 \%$ of cardiac output).

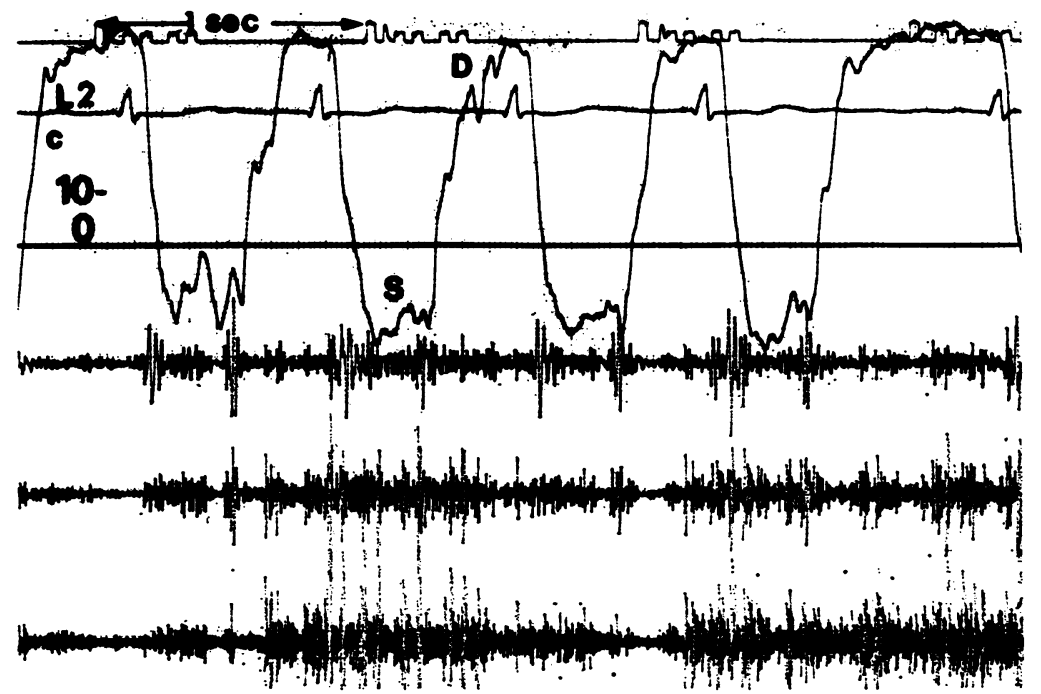

FIG. I4 Mitral valve flow velocity trace in a patient with moderate stenosis and a moderate central regurgitation. Recording at the centre of the annulus (same patient as in Fig. 13). Note the conspicuous negative systolic wave. The amplitude of the $D$ wave is noticeably higher than in Fig. 13 , and the indentations much less pronounced. 


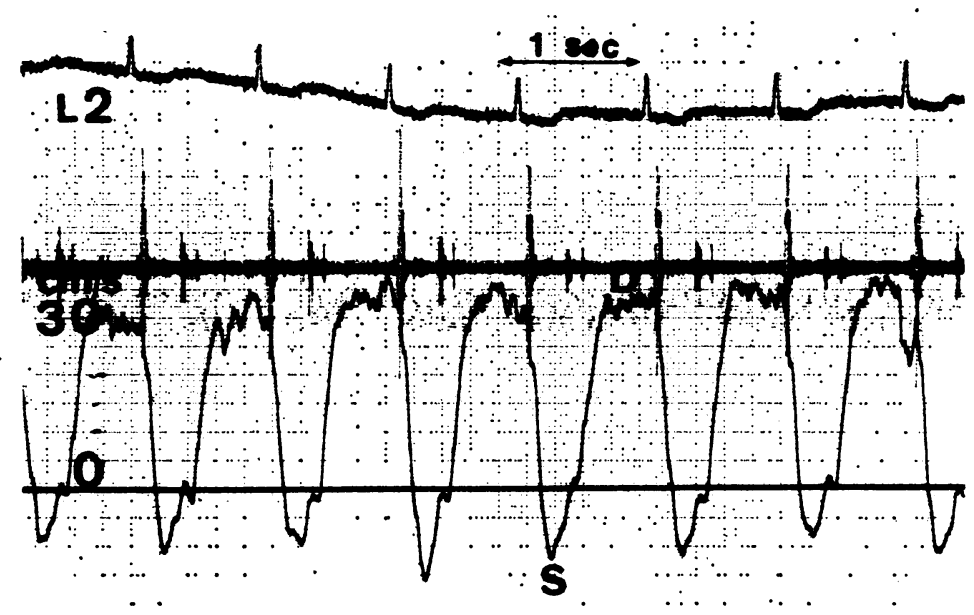

FI G. I5 Mitral valve flow velocity in a patient with mild stenosis and mild regurgitation. The curve shows a small negative $S$ wave, and characteristic indentations occurring at the peak of the $D$ wave which is of normal magnitude (Case 31 , calculated mitral area $1.6 \mathrm{~cm}^{2}$, volume of regurgitation: $10 \%$ of cardiac output).

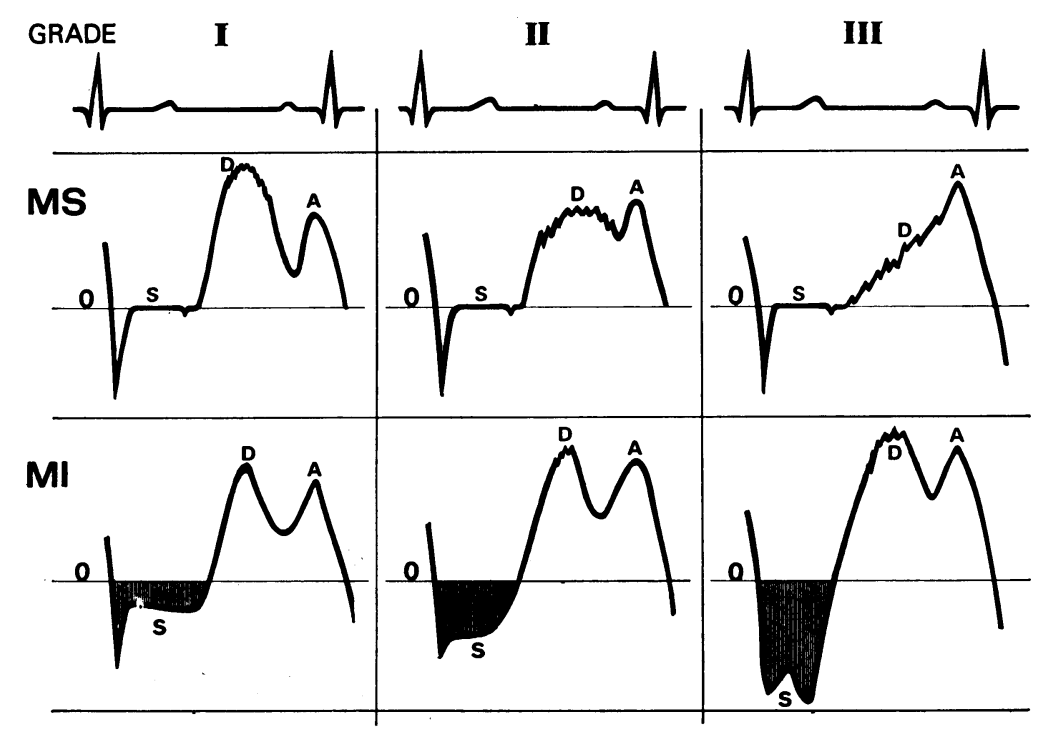

FIG. I6 Patterns of mitral valve flow velocity in patients with pure mitral stenosis or pure mitral regurgitation. Grades 1,2 , and 3 correspond, respectively, to mild, moderate, and severe disease. Upper row: mitral stenosis. The greater the severity of the stenosis, the earlier the indentations are seen on the $D$ wave and the more gradual is its ascending slope. The amplitude of the $A$ wave varies inversely with that of the $D$ wave. Lower row: mitral regurgitation. The $S$ wave is entirely negative, and becomes more so as the degree of regurgitation increases (see text). 
diagnosing tricuspid valve disease using pattern recognition. It, therefore, seemed reasonable that a similar technique, applied to the mitral valve by means of the transseptal approach, might lead to a new method of diagnosing mitral valve disease and also shed new light on the timing and pattern of mitral flow disturbances and their relation to auscultatory findings. The present paper will be limited to the diagnostic value of the method and further applications will be considered in a later publication.

\section{Hazards of the transseptal technique}

The transseptal route often has the reputation of being dangerous: this is unjustified, provided it be performed by experienced hands. In a series of I 100 cases, Forman and Soulié (J. Forman, 1973, personal communication) had only 8 cases of haemopericardium, never caused by the atrial septal puncture itself, but by manoeuvring the micromanometer. These accidents only occurred in patients with distended and fragile left atria. Of these 8 cases, 7 were operated on successfully, and the other died after having 2 prosthetic valves inserted. These data suggest that the hazards of the transseptal route, when properly performed, are not higher than those of other catheterization or angiographic procedures. In our personal series (IOO cases) no adverse incidents occurred other than transient atrial or ventricular arrhythmias.

\section{Diagnostic value}

In our 33 patients with mitral valve disease, we consistently found that the mitral flow velocity trace was different from the normal flow velocity pattern we described in the first part of this study (Kalmanson et al., 1975), and furthermore that particular types of pattern corresponded, respectively, to mitral stenosis and to mitral regurgitation (Fig. I6). In all patients with mitral stenosis, we found anomalies of the $\mathrm{D}$ wave, which consisted of the occurrence of indentations of the ascending limb or of its summit, in some a decreased slope of this ascending limb and a decreased height of its peak. In all patients with mitral regurgitation, the $S$ wave was found to be partly or totally negative. This group included 2 patients in whom routine catheterization and the dilution technique did not suggest regurgitation, the latter being diagnosed by the existence of a pansystolic murmur which decreased with inhalation of amyl nitrite in patients with a history of acute rheumatism. This finding suggests that the velocity recording method might be more sensitive than the classical ones of pressure measurements and dye dilution. In patients with both stenosis and regurgitation, we found both the diastolic and the systolic anomalies described above for the corresponding lesions.

From these correlations, it can be deduced that the presence of indentations on the ascending limb or on the summit of the $\mathrm{D}$ wave is a reliable clue to the diagnosis of mitral stenosis, and that the occurrence of a negative wave during part or all of systole indicates the presence of mitral regurgitation.

\section{Assessment of severity}

Furthermore, we found a satisfactory correlation between particular types of anomalous pattern and the severity of the mitral lesion as assessed by the clinical and haemodynamic data (Fig. 16).

Mitral stenosis Comparison of the curves with the clinical and haemodynamic grading of the disease shows that the earlier and the larger the characteristic indentations, and the smaller the slope of the ascending limb of the $D$ wave, the more severe the stenosis. More precisely, in all of the mild cases, small indentations appeared only on the latter half of the ascending limb, which had a normal slope and magnitude. In severe stenosis, on the other hand, indentations began very early, almost at the level of the zero line, were coarse, and occupied all the ascending limb, the slope of which was much less than normal. In some cases, in sinus rhythm, the $\mathrm{D}$ wave was entirely replaced by a unique ascending segment, rejoining the ascending limb of the A wave which was increased in magnitude. In moderate cases, intermediary patterns were found with indentations starting in the middle of the ascending limb of the D wave. Furthermore, the traces in patients with moderate or severe stenosis showed the typical pattern at the site of the commissure, whereas at the centre of the mitral ring the curve disclosed a lower grade pattern, i.e. steeper ascent of the $D$ wave, later occurrence of the indentations which are less pronounced, and higher velocities. This demonstrates that the flow velocity profile in such cases is not flat across the mitral annulus.

Mitral regurgitation The comparison between the depth of the negative systolic $S$ wave and the severity of the regurgitation assessed by clinical and haemodynamic data also showed a very satisfactory relation: the larger the negative $S$ wave, the more severe the mitral regurgitation. The depth of the negative wave varied slightly across the mitral ring in most of the patients and it should be pointed out that this negative wave may be elicited only at one particular point of the annulus, hence the necessity of exploring carefully the whole area before excluding the possibility of a small leakage through the valve. 
Associated mitral stenosis and regurgitation These criteria for the severity of stenosis and regurgitation also held true for each of the associated lesions. In most cases, the patterns suggestive of maximum severity were recorded at different sites for each type of lesion: at the commissural areas or near the ring for the stenosis, and at the centre for the regurgitation. In other words, these patterns of mitral valve flow velocity provide good clues to the severity of the disease of the valve.

\section{Interpretation of anomalies}

In the first part of this report interpretation and the physiological significance of the normal flow velocity curves were derived from experimental data relating to velocity profile and variations in size of the mitral ring. Unfortunately, no such data are yet available for abnormal mitral valves, and therefore similar inferences cannot be drawn. However, our findings may suggest the following hypothesis concerning the pathophysiological interpretation of the curves.

Pure mitral stenosis The characteristic indentations are most likely to reflect the turbulence generated by the impedance to transmitral blood flow caused by stenosis, and are synchronous with the diastolic murmur. Experimental data on mitral stenosis phasic flow disturbances are not available; however, it is only logical to assume that they are similar to those found by Spencer and co-workers for experimental coarctation of aorta in dogs (Spencer, Johnston, and Meredith, 1958). It is probable that the intensity of the turbulence increases with the degree of stenosis, and that below a critical value of the valve area, the flow volume decreases. Our velocity findings are as a whole consistent with this. As long as the stenosis is mild, turbulence - and the corresponding indentations on the flow velocity curve - is small and appears only when the stenosis has haemodynamic consequences, i.e. for high velocities. Flow is maintained and, therefore, flow velocity remains normal or can even be increased. This explains why most of the ascending limb of the $D$ wave has a normal slope. On the other hand, in severe stenosis, turbulence is important and occurs very early after the opening of the valve. Simultaneously flow is decreased. This accounts for the occurrence of early and pronounced indentations and may account for the lessening of the slope of the ascending limb of the $D$ wave. An alternative explanation for this decreased slope is the decreased sensitivity of the equipment to high velocity turbulent flow (Tunstall-Pedoe, 1972). Such a decreased sensitivity probably accounts also for our values of peak velocities being lower than one might reasonably expect, since stenosis should be assumed to raise transmitral flow velocities considerably. Such a non-linearity does not affect in the least the value of the method since the latter relies on a pattern recognition rather than on the knowledge of the accurate value of flow velocities. Furthermore, in patients with sinus rhythm, the more severe the stenosis, the greater the flow velocity during atrial contraction, since a larger blood volume then remains in the atrium after the initial filling; hence our finding of a high $\mathrm{A}$ wave in such cases. For moderate stenosis, time of occurrence, and intensity of the turbulence, and therefore of the indentations of the curve, are intermediate.

Finally to summarize, three different patterns can be distinguished according to the severity of the stenosis (Fig. 16), which fit satisfactorily with the requirements for clinical decisions. However, the real situation is more complex, since degrees of severity are not sharply defined and since the velocity profile at the mitral ring is not flat, as it has been shown to be for the normal valve. This is the reason why in a certain number of patients a particular type of pattern can be recorded at one site, e.g. at the commissural area, at the site of the stenosis, while a lower grading pattern may be encountered at the centre of the mitral ring. Such possibilities, however, do not restrict the diagnostic value of the method, but on the contrary allow us to refine the accuracy of the grading.

Pure mitral regurgitation Quite clearly the negative $S$ wave provides a direct record of the reversal flow. As a whole, the deeper and broader the $S$ wave, the greater the regurgitation. However, this rule may be modified in particular cases, namely in patients with abnormal chordae tendineae or papillary muscle dysfunction in whom regurgitation may be limited to a narrow jet. The grading of severity therefore, can only be assessed after carefully exploring the mitral ring with the catheter tip. In patients with mild regurgitation, a negative $S$ wave, of low amplitude, especially when endsystolic in timing, may be detected only at certain sites, whereas the curve appears normal elsewhere. On the other hand, Doppler catheterization allows the detection of small leaks of blood through the mitral valve, that otherwise are not haemodynamically great enough to be disclosed by more classical procedures. In patients with severe regurgitation, the negative wave lasts throughout systole, encompasses most of the mitral area, and may even persist beyond the aortic component of the second heart sound. The finding in two of our cases of decreased diastolic velocities may be surprising since these are expected to be increased in mitral regurgitation. This discrepancy might be explained by the fact 
that the direction of blood flowing into the left ventricle during diastole is most likely to be different in these cases from that of the regurgitant flow. The catheter tip is then no longer parallel to the direction of the blood flow during diastole, which accounts for the loss of linearity.

Associated mitral stenosis and regurgitation The above comments for isolated lesions also hold true. Most often both lesion patterns show up on the same trace. But this may not be immediately conspicuous and may require careful exploration of the mitral ring in the search for an associated lesion.

\section{Limitations of method}

I) With present catheters, Doppler catheterization of the mitral valve is not always feasible. The most important obstacle is the difficulty - and sometimes the impossibility - in certain patients with small hearts and hyperkinetic states of achieving satisfactory immobilization of the catheter tip. More specifically, the anterolateral commissure and the centre of the mitral ring can usually be explored, while the procedure is much more difficult for the posteromedial commissure. Inadequate exploration of all sites may cause a lesion to be missed. It is to be hoped, however, that technical improvements will make this sequence of routine exploration easier and more feasible.

2) The present diagnostic method does not rely on the accuracy of absolute value of flow velocities in terms of $\mathrm{cm} / \mathrm{s}$, but rather on comparison of the recorded curves with characteristic patterns. This pattern recognition method seems particularly suitable for tackling the problem of evaluating mitral valve disease, since no universal definition exists for the accurate numerical grading of different degrees of severity. Recent emphasis had been put on such methods which are linked to the Fuzzy Sets theory proposed by Zadeh (Zadeh, 1972; Kalmanson, 1973).

\section{Conclusion}

In spite of some difficulties, the Doppler velocimetric catheterization of the mitral valve using the transseptal route provides a unique opportunity of assessing the diagnosis and evaluating the severity of mitral valve disease, by offering a direct, graphic representation of phasic flow velocity disturbances which can be classified using a pattern recognition method. It seems particularly adequate for detecting combined lesions of the valve and appraising their respective importance. Furthermore, it provides a new approach for understanding mitral haemodynamic disturbances on a beat-tobeat basis and should lead to new correlations with other haemodynamic or phonocardiographic events.

We are greatly indebted to Dr. D. Tunstall-Pedoe, St. Bartholomew's Hospital, London, for correcting the English translation and for his valuable suggestions.

\section{References}

Forman, J., Laurens, P., and Servelle, M. (1962). Le cathétérisme des cavités gauches au micromanometre par voie transeptale. Archives des Maladies du Coeur et des Vaisseaux, 55, 601.

Kalmanson, D. (1973). Recherche cardio-vasculaire et thérie des ensembles flous. La Nouvelle Presse Médicale, 2, 2757.

Kalmanson, D., Bernier, A., Veyrat, C., Witchitz, S., Savier, C. H., and Chiche, P. (1975). Normal pattern and physiological significance of mitral valve flow velocity recorded using transseptal Doppler ultrasound catheterization. British Heart fournal, 37, 249.

Kalmanson, D., Derai, C., and Novikoff, N. (1971). Le flux tricuspidien étudié chez l'animal et chez l'homme par cathétérisme vélocimétrique directionnel. Aspect normal, variations physiologiques et applications diagnostiques. Archives des Maladies du Coeur et des Vaisseaux, 64, 854 .

Kalmanson, D., Toutain, G., Novikoff, N., Derai, C., Chiche, P., and Cabrol, C. (1969). Le cathétérisme vélocimétrique du coeur et des gros vaisseaux par sonde ultrasonique directionnelle à effet Doppler. Rapport préliminaire. Annales de Médecine Interne, 120, 685 .

Spencer, M., Johnston, R., and Meredith, J. (1958). The origin and interpretation of murmurs in coarctation of the aorta. American Heart fournal, 56, 722.

Tunstall Pedoe, D. S. (1972). Diagnosis of aortic incompetence using directional Doppler blood velocity measurements - problems of quantitation. In Fluid Dynamic Measurements in the Industrial and Medical Environments, p. 325. Ed. by D. J. Cockrell. Leicester University Press, Leicester.

Zadeh, L. A. (1972). Outline of a new approach to the analysis of complex systems and decision processes. Memorandum. ERL - M 342. Electronics Research Laboratory, University of Berkeley, California, U.S.A.

Requests for reprints to Dr. D. Kalmanson, Fondation Ophtalmologique A. de Rothschild, 29 rue Manin, 75019 Paris, France. 